\title{
Influence of the attack angle on the performance of vibratory cultivators
}

\author{
N E Gheorghiță ${ }^{1}$, S Șt Biriș ${ }^{1}$ \\ ${ }^{1}$ Faculty of Biotechnical Systems Engineering, Politehnica University, Bucharest, RO \\ evelin_gheorghita@yahoo.com
}

\begin{abstract}
The effect of working tools on agricultural soil, materialized either in displacements or in elastic or plastic deformations of materials, indicates the possibility of using the resonance phenomenon according to their physico-mechanical properties and the degree of variation to one and the same material, resulting also in the possibility of reducing energy consumption. Thus a theoretical study has been carried out to identify the advantages and problems related to one of the most important elements of the oscillatory tillage tools. Finite Element Method was used to analyse three constructive solutions of the same vibratory working tool, for which it was changed their angle of attack for different values of draft force. Keywords: manipulation, cultivaltors, stress
\end{abstract}

\section{Introduction}

Tillage is basically a mechanical manipulation of the soil performed for obtaining suitable conditions for seed germination, establishment and its growth. It results in good physical condition of the soil known as soil tilth. Primary and secondary tillage manipulation are the two different types of operations required for cultivation of any kind of crop [3].

Oscillating mode tools have several advantages over non oscillating one. Oscillating tools requires less draft as compared to non oscillating one [3]. Therefore, oscillatory tillage tool can resolve the problems related to tillage applications.
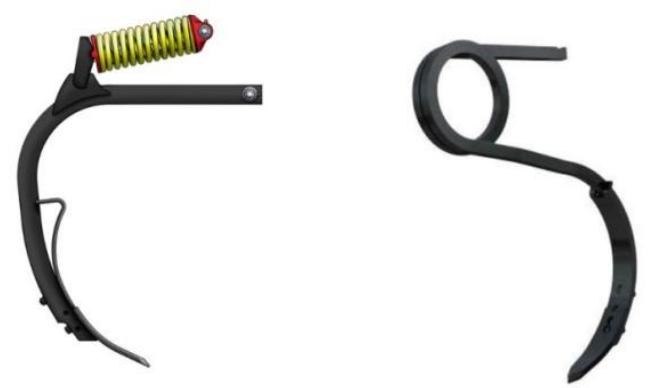

Figure 1. Elastic supports for the working bodies of cultivators [5]

Finite elements analysis of structures emerged as a necessity [1,2] to simplify and reduce the cost of testing in operation or under simulated and accelerated regimes, it can approximate to within acceptable precision the areas of maximum (critical) stress [1], the maximum stress and even the lifetime of a structure. 


\section{Materials and methods}

The cultivator that has been chosen for the study is a trailed cultivator, designed to operate at peak level in both dry years and those with more precipitation. Models in the product range range from 4.1 to 8.7 meters [5].

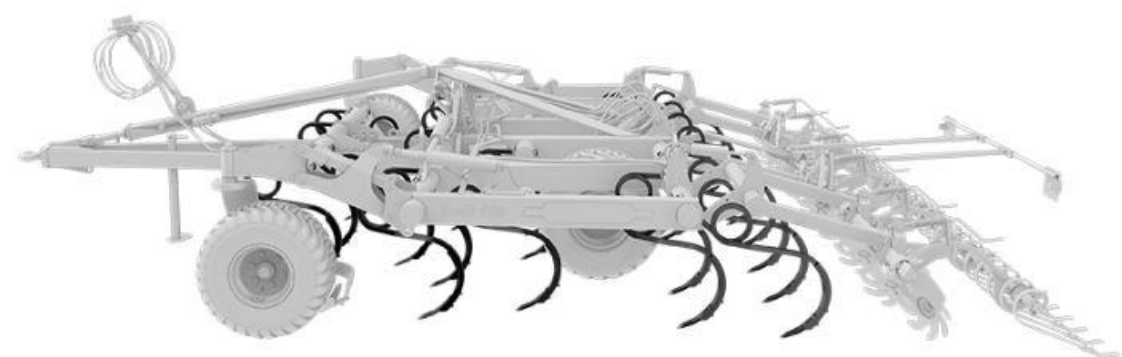

Figure 2. Positioning of tines on the cultivator frame [5]

Past research also revealed that amplitude, frequency and tractor velocity are very important parameters affecting the performance of oscillatory tillage. The above three parameters are usually combined into a velocity ratio term which is the ratio of maximum tine tip velocity to carrier ground velocity[4] :

$$
\lambda=\frac{v_{x(\max )}}{v_{0}}=\frac{a \omega \cos \gamma}{v_{0}}
$$

Where:

$\boldsymbol{v}_{\boldsymbol{x}(\mathbf{m a x})}=$ max velocity of tool tip $(\mathrm{m} / \mathrm{s})$;

$v_{0}=$ tool carrier velocity relative to ground, assumed horizontal $(\mathrm{m} / \mathrm{s})$;

$\mathrm{a}=$ tool tip oscillation amplitude referenced from the mid-point and measured perpendicular to the tool reference axis (m);

$\boldsymbol{\omega}=2 \boldsymbol{\pi} \mathrm{f}$, tool angular velocity relative to tool carrier $(\mathrm{rad} / \mathrm{s})$;

$\mathrm{f}=$ tool oscillation frequency $(\mathrm{Hz})$;

$\gamma=$ tool oscilation angle , reference from the vertical direction $\left({ }^{\circ}\right)$.

The tool oscillation angle can be changed by varying the position of the cutting tip relative to the pivot point [4] (Fig 3).
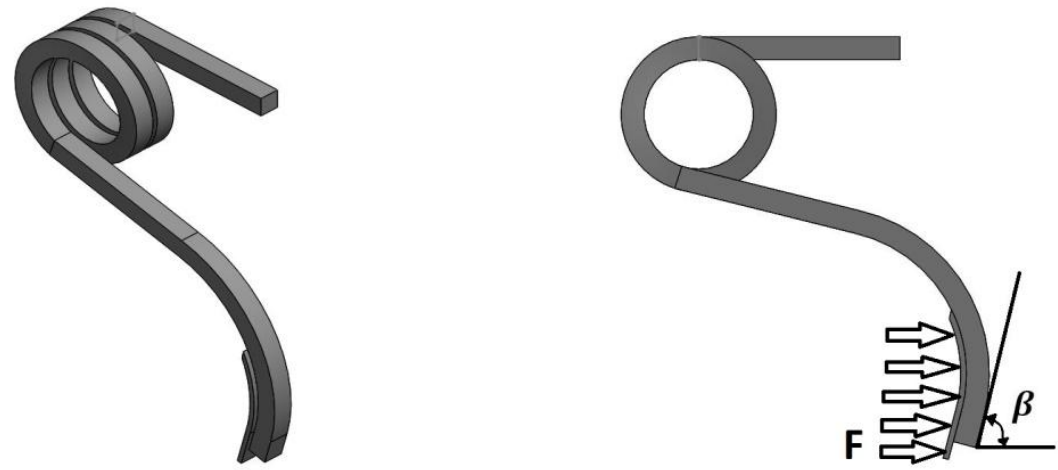

Figure. 3. Geometric model of the support used in the analysis

On the selected support acts the force resulting from the interaction with the soil(F), applied to the active surface of cutting of the support.

For various constructive solutions and results are used different values for the attack angle $\boldsymbol{\beta},\left(65^{\circ}\right.$, $\left.70^{\circ}, 75^{\circ}\right)$, and force $\mathrm{F}(1000,2000,3000 \mathrm{~N})$. 
From previous studies it is recommended that the angle $\beta$ must not exceed values of approximately $80^{\circ}$ after the forces are applied. For the stress and deformation analisys has been used FEM.

\section{Results and discussion}

The results of the first analysis of the model of support are presented in the following figures. They consist of the distribution of equivalent stress according to the Von-Mises criterion, and the distribution of total deformations for the type of support, at at an attack angle $\boldsymbol{\beta}=\mathbf{6 5}^{\circ}$ and different values of draft force $\mathrm{F}$.
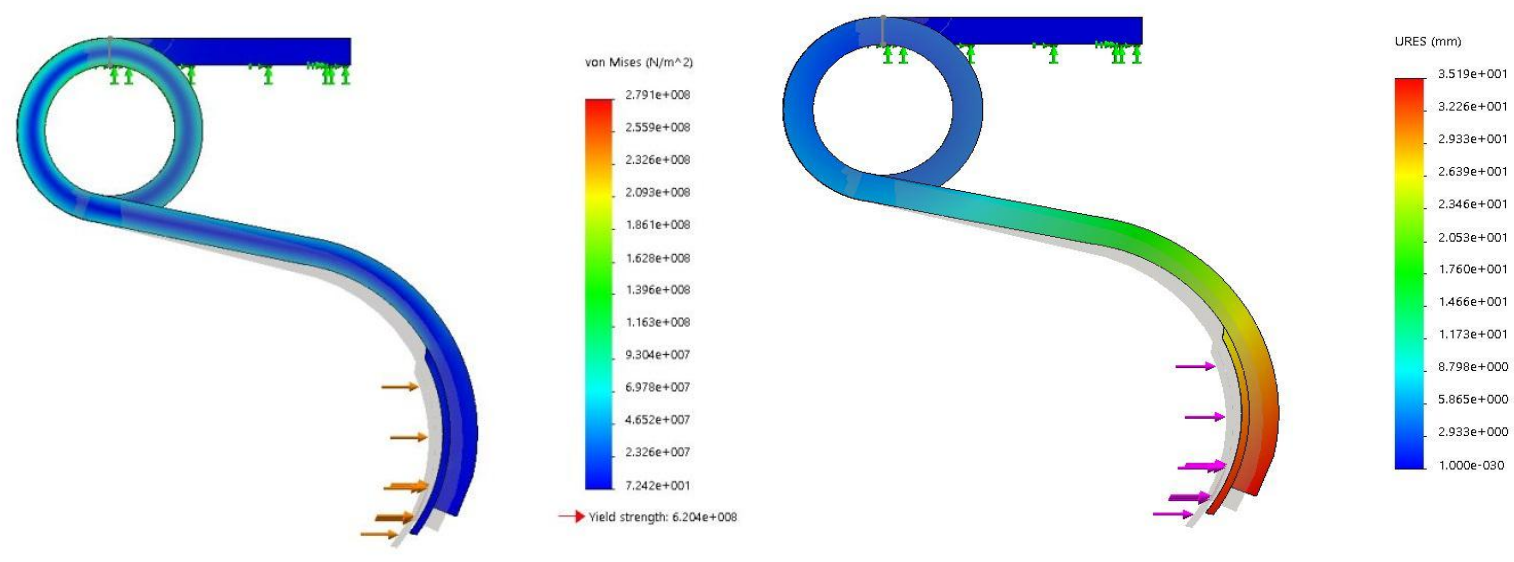

Figure 4. Distribution of stress and deformations for $\boldsymbol{\beta}=\mathbf{6 5}^{\circ}$ and $\mathrm{F}=1000 \mathrm{~N}$
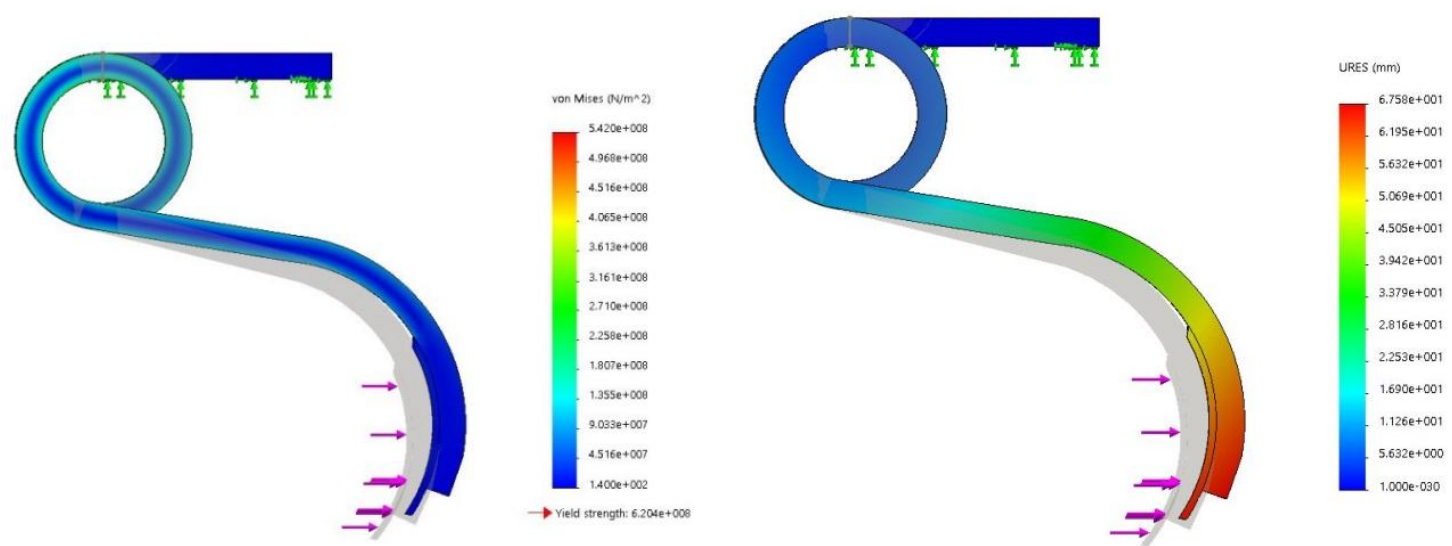

Figure 5. Distribution of stress and deformations for $\boldsymbol{\beta}=\mathbf{6 5}^{\circ}$ and $\mathrm{F}=2000 \mathrm{~N}$ 

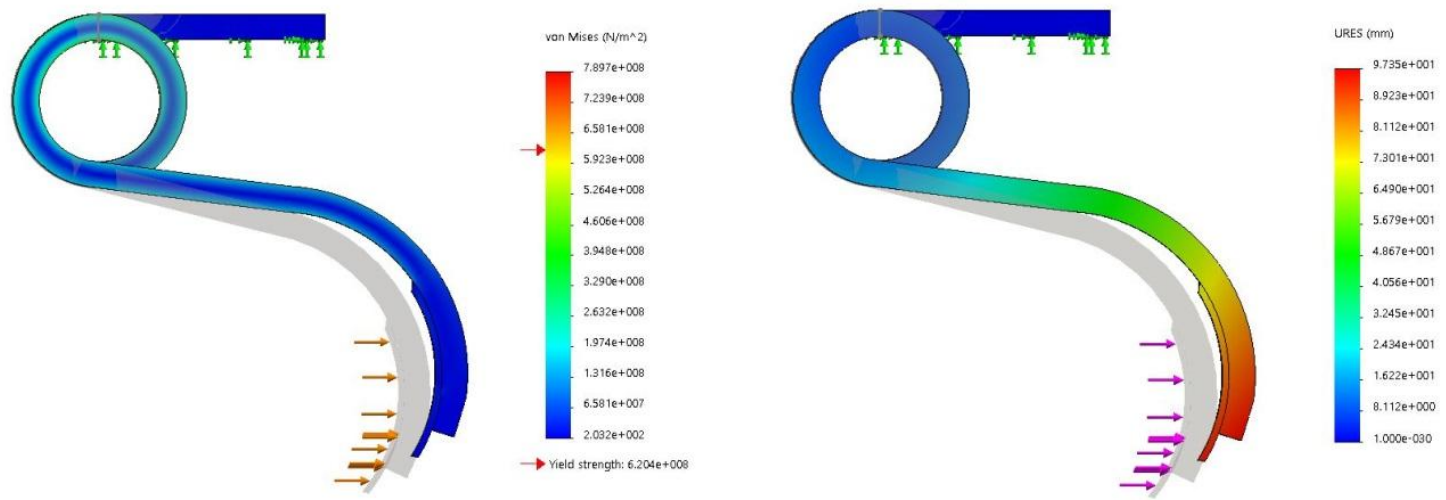

Figure 6. Distribution of stress and deformations for $\boldsymbol{\beta}=\mathbf{6 5}^{\circ}$ and $\mathrm{F}=3000 \mathrm{~N}$

The results of the second analysis of the model of support are presented in the following figures. They consist of the distribution of equivalent stress according to the Von-Mises criterion, and the distribution of total deformations for the type of support, at at an attack angle $\boldsymbol{\beta}=\mathbf{7 0}^{\circ}$ and values of draft force $\mathrm{F}$ being $1000 \mathrm{~N}$ and $2000 \mathrm{~N}$.
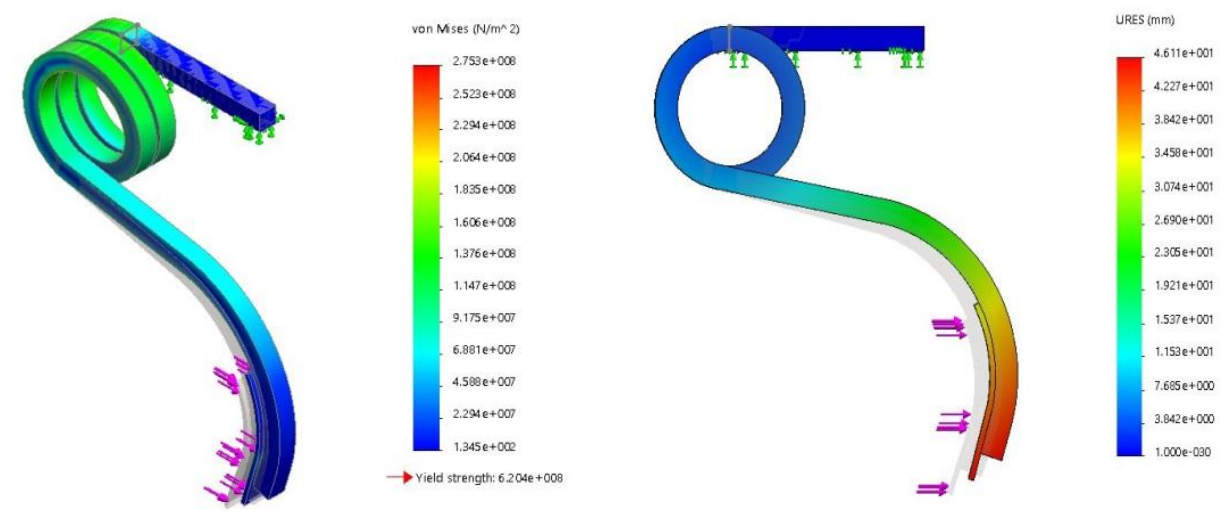

Figure 7. Distribution of stress and deformations for $\boldsymbol{\beta}=\mathbf{7 0}^{\circ}$ and $\mathrm{F}=1000 \mathrm{~N}$
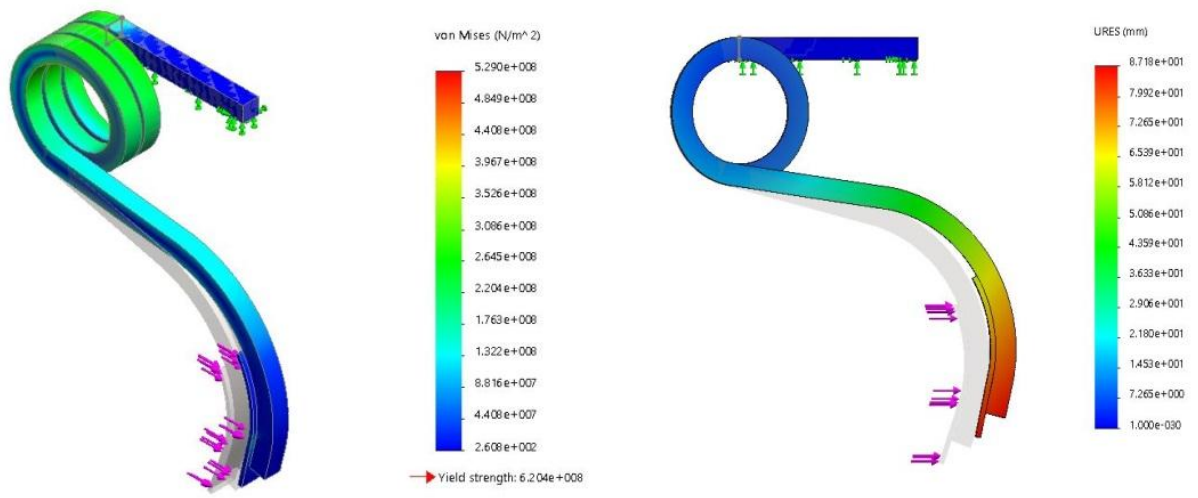

Figure 8. Distribution of stress and deformations for $\boldsymbol{\beta}=\mathbf{7 0}^{\circ}$ and $\mathrm{F}=2000 \mathrm{~N}$

The results of the third analysis of the model of support are presented in the following figures. They consist of the distribution of equivalent stress according to the Von-Mises criterion, and the 
distribution of total deformations for the type of support, at at an attack angle $\boldsymbol{\beta}=\mathbf{7 5}^{\circ}$ and the values of draft force $\mathrm{F}$ being $1000 \mathrm{~N}$ and $2000 \mathrm{~N}$.
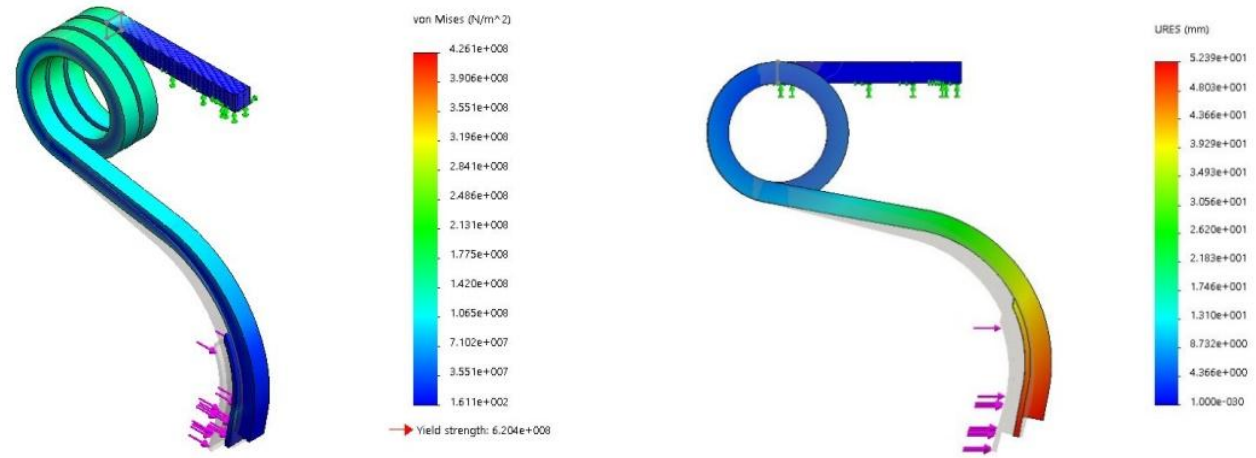

Figure 9. Distribution of stress and deformations for $\boldsymbol{\beta}=\mathbf{7 5}^{\circ}$ and $\mathrm{F}=1000 \mathrm{~N}$
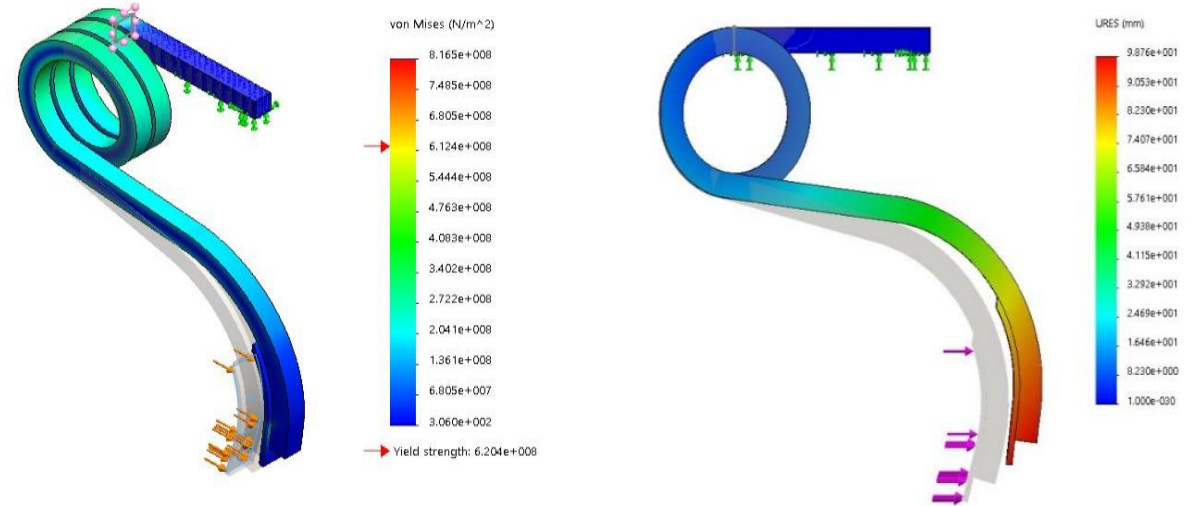

Figure 10. Distribution of stress and deformations for $\boldsymbol{\beta}=\mathbf{7 5}^{\circ}$ and $\mathrm{F}=2000 \mathrm{~N}$

In the figures presented above is showed the distribution of equivalent stress and the areas where the maximum values are recorded are on the superior part of the tool. Figure 11 presents the variation of total deformations of the surface of application of force $F$ on the support based on the angle of attack $\beta$, depending on the value of draft force for three analyzed constructive solutions.

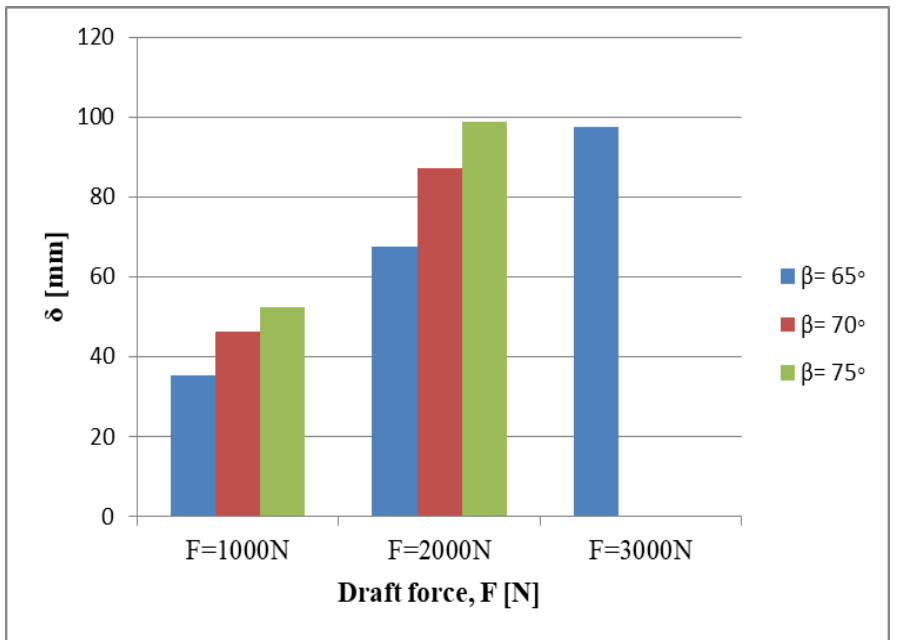

Figure 11. Variation of total deformations with draft force and the angle of attack 


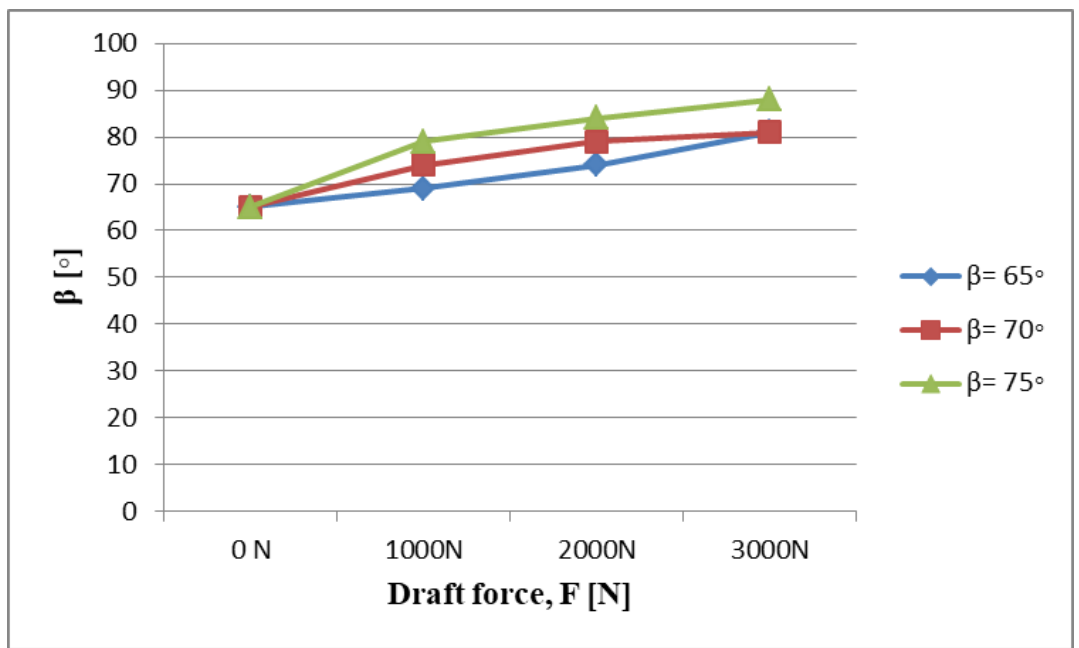

Figure 12. Variation of the angle of attack with draft force and constructive solution

\section{Conclusions}

From the analysis of deformations distribution (Fig. 4-10) and the graphical variation of the size of deformations in the surface of application of force F (Fig. 11) it results that the support has deformations of almost $100 \mathrm{~mm}$ if the draft force exceeds $3000 \mathrm{~N}$ when the attack angle is $65^{\circ}$ and if the draft force exceeds $2000 \mathrm{~N}$ when the attack angle is $70^{\circ}$.

From the analysis of the results it is showed that the attack angle $\beta$ exceeds values of $75-80^{\circ}$, which represent the upper limit to ensure tool stability in the soil according to studies, if $\mathrm{F}$ is larger than 3000 $\mathrm{N}$ for option 1 and higher than $2000 \mathrm{~N}$ for option 2 and $1000 \mathrm{~N}$ for option 3.

This study reports on further research to be conducted to evaluate the effect of attack angles on cultivator performance even better. The objectives of the research must be to find the most efficient oscillation angle for draft reduction and low power requirement.

\section{References}

[1] Bhatti M.A., 2003, Finite Element Analysis. Theory and Applications, Zephyr Copier, Iowa State University.

[2] Duarte C.A., Hamzeh O.N., Liszka T.J., Tworzydlo W.W., 2001, A generalized finite element method for the simulation of three-dimensional dynamic crack propagation, Computer Methods in Applied Mechanics and Engineering 190 (15-17), pp. 2227-2262.

[3] Gowripathi R., Himanshu C., 2018, A review on effect of vibration in tillage application, IOP Conference Series: Materials Science and Engineering

[4] Shahgoli, Gholamhossein et al., 2009, "The Effect of Oscillation Angle on the Performance of Oscillatory Tillage." Soil and Tillage Research 104.1, 97-105. Web.

[5] ***Cultivators and harrows for all soil types, 2015, VäderstadAB, Sweden. 